\title{
A COMBINED DOCTRINE OF KNOWLEDGE FOR PLATO
}

\author{
E. A. LAIDLAW-JOHNSON \\ University of Rochester
}

One of the many puzzling aspects of the Theaetetus is its aim. Just what is Plato's project? At the outset of the dialogue, Socrates asks about the nature of knowledge. During the course of the dialogue, several definitions of knowledge are proposed and rejected. The dialogue ends with Socrates advising Theaetetus that any further consideration into the nature of knowledge will be improved as a result of their deliberations. The dialogue does not establish a definition of knowledge, nor does it give definitive criteria for being an object of knowledge. The project of the dialogue is simply an open-ended inquiry into the nature of knowledge. However, this inquiry is not fruitless. Through the refutations of the proposed definitions of knowledge, the seeds of a Platonic doctrine of knowledge are sown. The project of this paper is to examine one of these refutations and to propose a doctrine of knowledge that grows out of that refutation.

You will find a whole profession to prove that true belief is not knowledge...The profession of those paragons of intellect known as orators and lawyers. There you have men who use their skill to produce conviction, not by instruction, but my making people believe whatever they want them to believe. You can hardly imagine teachers so clever as to be able, in the short time allowed by the clock, to instruct their hearers thoroughly in the true facts of a case of robbery or other violence which the hearers had not witnessed...And when a jury is rightly convinced of facts which can be known only by an eyewitness, then, judging by hearsay and accepting a true belief, they are judging without knowledge, although, if they find the right verdict, their conviction is correct.

Th. 201a-b'

In the Theaetetus, Plato refutes the definition of knowledge as true belief through the jury case described above. I shall clarify the import of this puzzling passage through the development of Plato's meanings of

'Plato, Theaetetus. All references to Plato's writings are from the translations contained in Plato: The Collected Dialogues, Edith Hamilton and Huntington Cairns, eds. (Princeton: Princeton University Press, 1963). Title Abbreviations are as follows: Eu., Euthydemus; Ph., Phaedo; R., Republic; Soph., Sophist; Th., Theactetus. 
"teaching" and "knowledge." In addition, I shall propose an innovative interpretation of Plato's doctrine of knowledge. After resolving several apparent paradoxes in the jury refutation, I shall discuss Miles Burnyeat's erroneous interpretations of this passage. The development of the proposed doctrine will aid in understanding Burnyeat's misinterpretation of the paradoxes.

\section{The Paradoxes ${ }^{2}$}

The counter example given in the jury passage contains several claims. One cannot teach another facts of a perceptual event. Time is somehow a restriction on the instruction of facts of a perceptual event. Facts about such an event can only be known by an eyewitness. Plato suggests that the decision of a jury as to whether or not a suspect is guilty of robbery can be based at best on the jury's acceptance of true beliefs. The jury cannot base its decision on knowledge. His reasoning is two-fold: a) the jury is not taught, but manipulated through a particular skill of the advocates and b) they jury is not made up of eyewitnesses and must depend on testimony. The first reason implies that if the jury could be taught the facts of the case, then the jury could base its decision on knowledge of the crime. The second reason implies that only if the members of the jury had been eyewitnesses to the crime could the jury base its decision on knowledge of the crime. Two critical and allegedly incompatible claims appear to be made here: $(1 \mathrm{~A})$ that knowledge can be acquired through teaching and (1B) that knowledge is only obtained through direct perception. Miles Burnyeat has noted that either (1A) or (1B) may be sufficient to refute the definition, i.e., to establish that the jury, at best, can base its decision on true beliefs and not knowledge of the crime and, hence, that knowledge and true beliefs are not identical. In order to affirm that (1A) is sufficient to refute the definition of knowledge as true belief, more must be said about Plato's thoughts on teaching. To make the case that (1B) is sufficient to refute the same definition, Plato's thoughts about perceptual knowledge must be detailed. I shall show that, when considered alone, both (1A) and (1B) are sufficient to refute the

${ }^{2} \mathrm{My}$ formulation of the paradoxes discussed here are reformulations of paradoxes which are both presented by Miles Burnyeat and discussed by Jonathon Barnes in "Socrates and the Jury," Proceedings from Aristotelian Society Supplement 54, (1980): 177. In a longer version of my essay I critically analyze Barnes' paradoxes. The paradoxes are first presented as they have been discussed in the Burnyeat and Barnes essay. The tentative nature of my initial presentation of the paradoxes is due to my unwillingness to interpret the jury passage without an understanding of the relationship between the key terms in the passage--knowledge and teaching. Upon investigating the Platonic conceptions of teaching and knowledge, I shall reformulate, and consequently, resolve the paradoxes. 
definition. Additionally, I shall assess the paradox resulting from the combination of (1A) and (1B) --that knowledge can be acquired through no means other than perception and that knowledge can be acquired by a means other than perception, namely teaching (hereafter referred to as the first paradox).

In relating the above passage to the earlier refutation of knowledge as perception, a second apparent paradox emerges. One claim of the jury refutation is that perception is necessary for knowledge. However, Plato refutes the definition of knowledge as perception by arguing that what can be perceived belongs to a different class of objects than what can be known. This claim and the refutation combined seem paradoxical. The paradox stems from Plato's sceming to maintain (2A) that in order to know that perceptual event of a crime, we must perceive it and (2B) that what can be perceived is a different sort of object than what can be known. (2A) and (2B) combined may entail that to be known some objects at least must be perceived and that a single object cannot be both perceived and known. An investigation into knowledge in general and perceptual knowledge in particular should shed light on this second apparent paradox. Having developed the Platonic notions of knowledge and teaching, I will return to both of these paradoxes.

\section{A Doctrine of Teaching}

In this section I will investigate Plato's concept of teaching by surveying the use of educational terms in the Corpus. Although terms such as learning and instruction are referred to in early dialogues and as such they may be less than ideal for guiding the interpretation of a later dialogue, they may aid in our understanding of the progression of Platonic thought. We shall see the later dialogues' usage of educational terms mirroring these earlier usages. In order to avoid misunderstandings about what entity does the learning for Plato, the investigation begins with an explanation of the distinction between soul and person.

An understanding of Plato's conception of teaching is best introduced through the perspective of how educational notions relate to Plato's soul/person ontological distinction. Before discussing the soul/person distinction, Plato's soul/body distinction must be addressed. In arguing that the existence of forms precedes the existence of bodies, Plato establishes that the soul is among the primal things, older than all bodies and the "prime source of all their changes and transformations" (Laws 10.892a). At Timaeus $43 \mathrm{c}$ the process of the soul's migration to the body is compared to the creation of the world. The creator..."fastening the courses of the immortal soul in a body which was in a state of perpetual influx and efflux." The body is initially rocked by sensation but becomes steady and rational once it is ensouled. In the Phaedo, Plato gives comparative characteristics of the soul and body. Soul is said to be immortal, intelligible, uniform, indissoluble, and even self consistent and invariable. 
Conversely, the body is human, mortal, multiform, unintelligible, dissoluble and never self consistent $(P h .80)$. In the same dialogue, Plato describes the soul as a long-lived thing that wears out several short-lived bodies much as a person wears out several coats in a life time ( $P h .87 d)$.

While this soul/body distinction will aid in our understanding of knowledge, it is the soul/person distinction through which Plato understands education. Based on the ontological distinction between the soul and body, I shall define a person as an ensouled body for the purpose of this paper. At Phaedo 75e, Plato equates learning with a person's recovery of knowledge of the forms that the person's soul lost at the moment of birth (or migration). Learning is a process of recollecting the invariable forms through the use of a person's senses upon objects in the sensible, changing world. A person is said to know when, through recollection, he recovers and retains the knowledge that was lost at birth. At Meno 81d, Plato introduces two types of learning: higher learning-the soul's acquisition of knowledge, and learning as meant in ordinary language--a man's recollection of a single piece of knowledge. The characterizations of learning in the Phaedo and Meno are compatible with the theory of knowledge via recollection--the doctrine introduced in the Meno. Clearly, both the Phaedo and Meno accounts of learning apply to a person's learning knowledge of the forms. It is the soul that initially acquires the forms and it is through a person's recovery via recollection that a person is said to have knowledge of the forms.

Educational terms are further discussed in the Euthydemus and Protagoras. At Euthydemus 278, Plato discusses two senses of the word "learn" with regard to a person: A) "when one has no knowledge at the beginning about something, and then afterwards gets the knowledge," and B) "when one already having the knowledge uses this knowledge to examine the same thing done or spoken." Socrates' discussion of absolute equality in the Phaedo produces examples of both of these senses of the word "learn." Recollecting, the form of absolute equality, is an example of the first sense of learn. Using the knowledge of absolute equality to describe two approximately equal sticks in the sensible world is an example of the second sense of "learning" ( $P h .74 d)$. This dual characterization of learning is not presented in terms of the soul acquiring knowledge, but rather as a person acquiring knowledge. A person has no knowledge of the forms until this knowledge is learned in the first sense through recollection prompted by the perception of instances of the forms in the perceptible world. Once possessing knowledge of the forms, a person uses his knowledge of the forms to learn, in the second sense, about sensible particulars that reflect the forms.

At Protagoras 321b, instruction is differentiated in to two types-professional, instruction geared to becoming a practitioner, and liberal, instruction that provides a foundation from which one recollects the forms. Later in the dialogue (326a-c), the occurrences of the ideals of virtue and 
gondness as perceived through poetry and music are given as examples of liberal instruction. This second lype of instruction seems to mesh with the Euthydemus conception of learning. Instructors are here referred to as teachers. Children are taught in the skills of reading, writing, and music. Hence they learn skills through which they are able to recognize the forms that their souls had forgotten at birth. It is hoped that the performance of these skills will engender recollection.

In the Sophist (229a-d), Theaetetus and the Stranger discuss two sorts of instruction, each of which is said to remedy a corresponding type of ignorance. The first sort of instruction is the "teaching of handicraft arts." Such teaching is labeled "education." However, through a description of ignorance, the Stranger mentions another sort of instruction that is said to correspond to "one very large and bad sort of ignorance" (Soph. 229c), namely, stupidity. Stupidity is exemplified by one who thinks he knows when he does not in fact know. Such ignorance is corrected through instruction via the dialectical process of admonition, that is, making one aware of inconsistencies in his thought. The scheme of instruction in the Sophist, then, provides for both knowledge of handicrafts, which is obtained through teaching, and elimination of knowledge-limiting conceptual obstacles, which is achieved through admonition. In the Sophist, Plato seems to reserve the use of "teaching" for reference to the instruction of skills.

Although the Republic contains very little about learning and instruction, a good deal is said in this dialogue about education. The concept of education here allows for the inclusion of instruction and admonition and also reveals a need for instruction to precede admonition. Children are trained early in music, and upon acquiring skill are given music whose speeches and tales reflect the form of the good in speech, harmony, and rhythm. "When children in their earliest play are imbued with the spirit of law and order through their music, ... (the lawful) spirit awaits on them in all things and fosters their growth, and restores and sets up again whatever was overthrown in the other (lawless) state." (R. 425a4-9)

In conclusion, each step of the educational process requires that students be prepared to acquire knowledge so that ignorance is not promoted. Teaching is something very different from one who knows conveying information to one who does not know, rather it is one who knows how to instill the appropriate disposition for recollection instilling this disposition in another. Children must be trained early in order to insure that all their training will result in the virtuous knowledge of the forms. Early training focuses on discipline that will be needed later in order to avoid sources of ignorance. Although the Republic's discussions of education center on the training that instills the proper disposition for recollection of the forms, the doctrine of knowledge I shall argue for maintains that in order to acquire or recollect any type of knowledge, a person must fulfill certain conditions. The conditions for recollection of 
the knowledge of a form is that one be exposed to sensible particulars that are instances of the form and that one has the disposition of a contradiction-free set of beliefs. As we shall see, a condition for knowledge of cognized external objects is that one be in a position to perceive the objects. In resolving the paradoxes previously presented, I shall return to these Platonic conceptions of education.

\section{The Combined Doctrine of Knowledge}

The aim of this paper is to produce an interpretation of a doctrine of knowledge that will enable the doctrines of knowledge found in earlier dialogues to yield a resolution to the paradoxes under discussion. When viewing the Theaetetus as an open-ended inquiry into the nature of knowledge, this aim may best be achieved by allowing the conclusions of the refutations in the Theaetetus to enrich the doctrines of knowledge found in the Phaedo and the Republic. In this section these doctrines will be discussed. It is assumed that each refutation in the Theaetetus is a rejection of a particular definition of knowledge. The critical task in uncovering a doctrine of knowledge that underlies the refutation is to understand both the definition to be refuted and its grounds for rejection. It is not unreasonable to suppose that Plato, in the later dialogues, maintains a doctrine of knowledge introduced in earlier dialogues. This will be the case, at any rate, so long as a single doctrine can be detected throughout the progression of the dialogues.

Plato first discusses knowledge in the Meno. In explaining how one can know something previously unknown, Socrates demonstrates that, when asked the proper question, even a slave boy can discover a geometrical truth previously unknown to him. Thought of in terms of the description of education discussed above, the slave boy 'learns' not by being told the truth by someone who knows, but by being appropriately prepared to recall the truth. Plato develops this method of acquiring knowledge into the doctrine of innate ideas in the Phaedo $(75 \mathrm{~b}-e)$. The eternal unchanging forms are known through recollection with the aid of perceptible objects. His doctrine of innate ideas establishes one type of knowledge--knowledge of the forms.

The Lovers of Beauty/Beautiful Things passages in the fifth book of the Republic (5.476c7-d3) might plausibly be taken to assert a broader doctrine of knowledge. Here Plato writes of "A man whose thought recognizes beauty in itself, and is able to distinguish that self-beauty and things that participate in it, and neither supposes the participants to be it nor it the participants." This passage appears to delineate two types of knowledge: knowledge of the forms and knowledge of cognized external 
objects. $^{3}$ A man in the mental state of knowing is said to be able to distinguish forms (the self-beautiful) from cognized external objects (things that participate in the self-beautiful). There are several reasons for interpreting the passage as referring to knowledge. In the case of distinguishing one object from another, one must first have the ability to recognize how the objects differ in order to have knowledge that they differ. This claim is defended by Plato in the Theaetetus' third refutation of knowledge as true belief together with an account. Actually, such an ability is necessary whether the distinction is based on true belief or knowledge. Second, the man in the passage is described as being awake as opposed to dreaming; one who dreams cannot apprehend forms. Third, the man above is also described as being in the mental state of knowing, as having knowledge ( $R .5 .476 \mathrm{~d}$ ff.) I take the Euthydemus' description of learning to mirror the Republic doctrine of knowledge. The forms are recollected through the learned disposition. These recollected forms are in turn used to acquire knowledge of cognized external objects.

The doctrine of the Phaedo differs from that of the Republic in that it deals solely with knowledge of the forms and hence makes no mention of knowledge of external objects. That Plato holds a different doctrine of knowledge in the Phaedo than in the Republic does not present a problem in interpretation so long as either the two doctrines are compatible or, if they are not compatible, Plato has presented good reasons to forgo the earlier doctrine. I take the doctrine in the Republic to be compatible with the doctrine in Phaedo. Both doctrines hold that there is a knowledge of the forms. The Phaedo doctrine explains how such knowledge is acquired. The root of the Republic doctrine (Book VI 70-80) maintains that without knowledge of the form of the beautiful, one cannot know beautiful things, but merely judges them to be beautiful. Thus, the Combined Doctrine holds $A$ ) that we acquire knowledge of the forms through recollection by use of our senses and B) that only with such knowledge are we able to know cognized external objects. However, in order to apply this doctrine to the refutation in the Theaetetus under discussion, I must argue that this broader doctrine of knowledge is consistent with the views put forth about knowledge in the Theaetetus. ${ }^{4}$

${ }^{3}$ While carrying out the investigation of the concept of knowledge, my reference to beautiful things as cognized external objects, instead of as simply sensible particulars, shall be explained.

${ }^{4}$ Before establishing that this doctrine is consistent with the Theaetetus, I must note that I shall not assume that Plato is committed to the claim that there are only two sorts of knowledge. Although I can find no textual evidence in the Theaetetus to support a third sort of knowledge, it is reasonable to assume that if Plato thought we could have knowledge of the forms and of cognized external objects, he might maintain that we are able to have knowledge of other types of objects-for instance, logical truths. It 
Early in the Theaetetus (146d) asked what knowledge is, Theactetus lists two sorts of knowledge--the sciences that one can learn from Theodorus and the crafts of workmen. Socrates does not challenge the possibility that there is more than one type of knowledge. Rather, he urges Theaetetus to look for what the sorts of knowledge he has listed have in common. Here at the outset of the dialogue, Socrates, when presented with several sorts of knowledge, offers no reason that would negate the possibility of a pluralistic doctrine of knowledge such as the Combined Doctrine from the Phaedo and the Republic. Although it is not uncommon for Plato's Socrates to begin an investigation into the nature of something with a list of the examples of that thing only to discard this list for an ideal of the investigated thing. Plato's methodology is different in the Theaetetus. He does not discard the list nor does he directly investigate the nature of the sorts of knowledge that Theodorus lists. Instead, Plato gnaws at the question of whether knowledge is perception until he gives a satisfactory answer in the refutation at 186c-e.

The Combined Doctrine of knowledge is given added meaning by considering the conclusion of Plato's refutation of knowledge as perception. "Knowledge is nothing but perception" (Th. 15le3) is ultimately refuted by the identification of a difference between the two-that knowledge, but not perception, can apprehend ousia (existence, essence). Yet in the argument against the notion that one cannot think what is not, after claiming that perception is not knowledge, Socrates establishes that when we perceive, we perceive what exists, just as when we think, we think what exists. An understanding of Plato's theory of perception as well as the meaning of ousia here are critical to interpreting this apparent contradiction.

Plato presents the Secret Doctrine theory of perception earlier in the Theaetelus. Modrak has persuasively argued for accepting this theory as Plato's. ${ }^{5}$ The process of visual perception according to the Secret Doctrine is described as follows:

As soon, then, as an eye and something else whose structure is adjusted to the eye come within range and give birth to the whiteness together with its cognate perception--things that would never have come into existence if either of the two had approached anything elsethen it is that, as the vision from the eyes and the whiteness from the thing that joins in giving birth to the color pass in the space between, the eye becomes filled with vision and now sees, and becomes, not vision, but a seeing eye, while the other parent of the color is saturated

may be the case that Plato might have held a pluralistic doctrine of knowledge that was inclusive of, but not limited to, the combined doctrine. ${ }^{5}$ Modrak, D. K., "Perception and Judgement in the Theactetus," Phroneșis, (1981): 38. 
with whiteness and becomes, on its side, not whiteness, but a white thing, be it stick or stone or whatever else may chance to be so colored. (Th.1562-e3) See Diagram below.

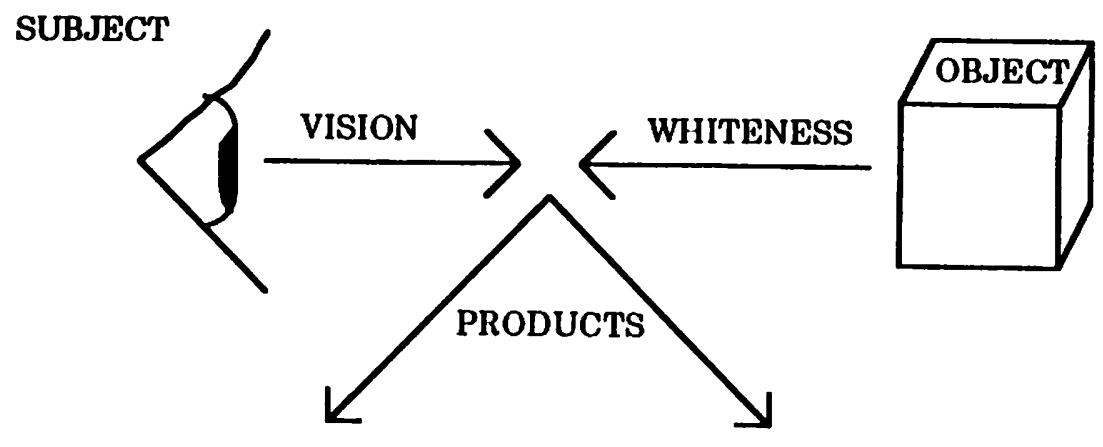

ASEEING EYE

COGNATE PERCEPTION OF

A WHITE THING: DATUM

The theory is generalized in terms of all types of sensory perception as follows: the two immediate products resulting from the interaction of a sense organ and a sensible object are the perceiving organ and a cognate perception of the object. For simplicity's sake I shall refer to the sense organ as the subject, the sensible particular as the object, and the cognate perception as the datum of the interaction. Although the perceiving organ is also a product of the interaction, further reference to it is unnecessary as it merely renames the organ upon activation of the organ's capabilities.

In his refutation of the thesis that knowledge is perception, Socrates is asserting that the operation of perception alone can produce such a datum as the perception of a white thing. When Socrates asserts that when a person sees, hears, and touches something, he sees, hears, and touches a thing that is (Th. 188e), he is contending that one of the products of the operation of perception is the apprehension of the existence of a perception of sensible particulars--those things that we can see, hear, and touch (colors, sounds, textures, etc.). To be precise, the datum is the apprehension that there is a white thing. However apprehending a datum is not having knowledge of an external object. Something more is needed to get from this single datum to knowledge of a cognized external object.

An additional epistemic requirement on the apprehension of a perception of an object is revealed in the refutation of knowledge as perception. This additional requirement also suggests that the forms help us to distinguish objects. At $186 \mathrm{~b}$, Plato details the sort of mental reflection 
about an object necessary for it to become an object of knowledge. The objects of knowledge in this instance are the hardness of a hard thing, and the softness of a soft thing, both are products of the operation of perception. At 186b6-9, Plato maintains that the ousia of hardness and softness and the fact that hardness and softness exist, and their oppositeness and the ousia of their oppositeness are all things that the mind judges through an internal process of reflection and comparison. Ousia may mean being in terms of an object's existence or being in terms of an object's essential nature. 6 Because Plato refers to the existence of hardness and softness independent of his use of ousia in this passage, a case can be made for ousia meaning an object's essential nature here. In the case of data, we know they exist because they are products of the process of perception. The existence of the forms according to Plato's ontology is independent of any human mental process. It would seem that existence is established in each case independent of ousia. If ousia were interpreted as an object's essential nature the passage in question would read as follows. The essential nature of hardness and softness and the fact that they exist, and their oppositeness and the essential nature of their oppositeness are all things that the mind judges through an internal process of reflection and comparison. Hereafter, ousia will refer to an object's essential nature.

I believe what Plato means by reflecting is reflecting on the nature of the object of knowledge, its ousia, and what is to be compared is the object with past experience through the use of forms. Hence, the mental reflection necessary with regard to knowledge of external objects includes reflection on the nature of the object and comparison of the object to past experience of external objects via one's knowledge of the forms. A cognized external object is a cognition made up of perceptions or data. Perceptions are rooted in the variable, unstable realm of becoming, but come to existence in the cognitive realm. The operation of perception begins in the realm of becoming. However, the Secret Doctrine maintains that the nature of the apprehension of a perception of a sensible particular is epistemic. The theory of perception tells us what conditions are necessary for successful perception of the world, i.e., what conditions are necessary for a successful transfer from the realm of becoming to the cognitive realm. In order to insure that the datum is indeed accurate one must be sure the usual conditions for perceptual success exist. For example, that one's vision is not hindered by external conditions or by the distance of the perceived object from the subject--the eye. Additionally, prior knowledge (of forms) allows one to produce the additional mental activity of comparison to transform data into an external object. The mind, through its awareness of the ousia of the external object, combines this

\footnotetext{
${ }^{6}$ The Modrak article contains a discussion of the possible meanings of ousia in this passage.
} 
single datum of the object with other data of the same object into the cognition of the external object. For example, the datum of the white thing and with the data of a several edged thing may by compared to previously perceived instances of the forms of squareness, straightness and equality to produce the cognition of the external object of a white box. The mind's knowledge of the forms of squareness, straightness and equality allows the mind to combine data in this manner. At any given moment, several human perceivers can talk about the cognized external object, provided they possess knowledge of the appropriate forms, because their sense organs are structurally similar and the object's structure remains constant, as do the external conditions of perception. The perceiver's awareness of the ousia of the external object--that it is a complex of data transformed into an external object via the comparative use of the forms--transforms the possession of infallible perceptions into knowledge of the external object. I have hinted here as to how we might use forms to produce cognized external objects. Much more must be said about this use of the forms in attaining knowledge of cognized external objects.

In his refutation of knowledge as true belief, Socrates refers to an instance of knowing an external object (a violent crime) as a case of knowing that is not identical to true belief. Under the Combined Doctrine of knowledge, all that Socrates has established is that one cannot acquire knowledge of a perceptual object solely through true belief. One needs initial data of the crime and the contribution of ousia of the external object which comes only when one has knowledge of the forms.

In refuting the first two versions of true belief plus an account as knowledge, Plato suggests nothing that would negate the Combined Doctrine of knowledge. The Combined Doctrine holds A) that we acquire knowledge of the forms through recollection by use of our senses and B) that only with such knowledge are we able to know cognized external objects. This doctrine is consistent with the restrictions that knowledge be such that a person who merely can signify what he thinks on a subject (the first rejected interpretation of knowledge as true belief plus logos) does not have knowledge of that subject and that a person who only can provide a complete catalogue of elements of a perceptible object (the second rejected interpretation of knowledge as true belief plus logos) cannot be said to have knowledge of the object. The Combined Doctrine's relation to the third refutation of knowledge as true belief plus logos, meaning true belief plus an account, cannot be determined until the meaning of "account" is made clear. Clarifying the meaning of this term and reconciling the new doctrine with this refutation is the next step in developing the Combined Doctrine. However, this step is beyond the scope of this paper.

Under the assumption of a successful reconciliation of the third refutation and the Combined Doctrine, a few conclusions about the outcome of the dialogue may be drawn. Even though at the outset 
Socrates insists on searching for a single characterization of knowledge, in the end, he implores us to learn from the inconsistencies revealed by the refutations. It would seem that a characterization of knowledge as true belief plus an awareness of the ousia of the object to be known may be satisfactory. However, the necessary conditions for the acquisition of each type of knowledge I have mentioned are very different. Knowledge is acquired quite differently in the case of forms than in the case of cognized external objects, hence a case can be made for breaking the characterization in two. True belief about the forms may be instilled through instruction, while ousia of the forms may come only with recollection. True belief about a cognized external object is rooted in the operation of perception, while an awareness of the ousia of such an object can only emerge upon having knowledge of the forms.

\section{The Resolution of the Paradoxes}

Given the discussions of knowledge and teaching, we can now untangle the paradoxes of the jury case. The jury is after knowledge of a cognized external event-a crime. In the Greek legal system, victims and alleged criminals were allotted a limited amount of time in which to present their case. The jury based its decision on the two parties' speeches. The jury had not witnessed the crime and hence could not meet the necessary dispositional conditions to obtain knowledge of that event. One's knowledge of the cognized external event is rooted in his having data of the event. Without perceiving the event, the best they jury could hope for in arriving at a decision is true belief.

We have seen why "you can hardly imagine teachers so clever as to be able, in the short time allowed by the clock, to instruct their hearers thoroughly in the true facts of a case of robbery or other violence that the hearers had not witnessed." (Th. 201a12-b3) First, a teacher's task is aimed directly at knowledge of the forms, and only indirectly at knowledge of external events, such as knowledge of a crime. The teacher enables the student to be in the best position in which to recollect forms i) through exposing the student to instances of the forms, and ii) through admonishing the student's contradictory viewpoints that lead to ignorance. Only after forms have been recollected can one use the knowledge of the forms to provide the ousia of the external event necessary to transform data into knowledge of the event. One might hold that such knowledge is in a way acquired through teaching, since forms are used in acquiring this knowledge. However, even if the knowledge that they jury sought were knowledge of the forms, the teaching process that instills in students a disposition to recollect forms takes year to complete. The time allowed by the clock is insufficient for this purpose. Additionally, no teacher can impart one of the requirements necessary to obtain knowledge of the robbery--the direct perception of the crime. A teacher cannot turn back the clock and make sure the jury is located such that it will be sure to 
witness the crime. A teacher can aid only in recollecting forms which the perceiver will use to transform data of the event's perceptual characteristics into knowledge of the external event.

The first paradox of the jury case is a product of the following two claims: (1A) that knowledge can be acquired through teaching and (1B) that knowledge is only obtained through direct perception. It is apparent now that (1A) alone is sufficient to refute the definition of knowledge as true belief. The appropriate question to ask is what is it about teaching that makes it impossible for the jury to obtain knowledge in this case through teaching. As suggested above, the process of teaching involved in recollecting the knowledge of the forms is lengthy. The prosecutor and defendant only have a limited amount of time in which to present their cases. Hence, even if such knowledge could be taught (and it cannot), the prosecutor and defendant do not have enough time to teach such knowledge to the jury. The Combined Doctrine of knowledge allows for the truth of (1A). Knowledge of the forms is acquired through teaching in that teaching both eliminates contradictions from a student's set of beliefs and exposes the student to sensible instances of the forms. Plato maintains that these two ingredients are necessary for the recollection of, and consequently knowledge of the forms.

The meaning of (1B) is ambiguous. (1B) may mean that through perception and no other means can one obtain knowledge. This meaning is wrong. Plato clearly maintains that admonition is a necessary part of the educational process and, hence, a necessary part of obtaining knowledge of the forms. Admonition is not essentially perceptual. Hence, knowledge of the forms is obtained in part through some non-perceptual means. A better meaning for (1B) may be that only through some use of perception is any type of knowledge obtained. Perception's role in the acquisition of knowledge of a cognized external object was detailed in the above discussion. Perception's role in the acquisition of knowledge of the forms is somewhat subtle. A necessary part of the process of education is exposure to instances of forms in sensible particulars. For example, a student hears an instance of harmony and sees instances of equality and beauty. Such hearing and seeing are examples of perceptions that are necessary for the recollection of knowledge of forms. Hence, the acquisition of the knowledge of forms and knowledge of cognized external objects requires perception. Both arms of the apparent paradox are true. Contrary to Burnyeat's suggestion, (1B) taken alone, under this interpretation, does not refute the definition of knowledge as true belief. However, Plato makes no claims that it can refute the definition. The unproblematic reformulation of the apparent paradox reads: (1 $\left.\mathrm{A}^{\prime}\right)$ knowledge of forms is acquired partially through teaching and $\left(1 B^{\prime}\right)$ the acquisition of all knowledge requires perception.

The second paradox is rooted in Plato's seeming to maintain (2A) that in order to know an object, we must perceive it and (2B) that what can be 
perceived is a different sort of object than what can be known. The resulting paradox reads that to be known, an object must be cognized and that one object cannot be both perceived and known. According to the Combined Doctrine, we can know forms and cognized external objects. Forms are not perceived: we perceive instances of forms. External objects are not directly perceived: the data from which these objects are cognized are perceived. Therefore, neither forms nor external objects are perceived. $(2 \mathrm{~A})$ is false and the paradox is resolved. Data are perceived. The datum (a white thing) and the cognized external object (a white box) are two distinct entities. Hence, the Combined Doctrine renders (2B) true; what can be perceived (data) is a different sort of object than what can be known (forms and external objects).

\section{Conclusion}

My analyses of knowledge and teaching have shown that knowledge cannot be directly transmitted through teaching. The acquisition of both sorts of knowledge requires the possession of a prior disposition. Acquisition of knowledge of a perceptual event requires the knower to be in a position to perceive that event and to possess knowledge of forms in order to cognize the event from perceptions. Knowledge of the forms is acquired only by someone possessing the disposition to recollect the forms. This disposition is acquired partially by being taught skills, partially by being exposed to instances of the forms as manifested in these skills, and partially by the elimination of sources of ignorance through admonishment. Teaching's partial contribution to the acquisition of the disposition to recollect forms is its only contribution to knowledge of the forms. Knowledge of the forms is obtained through perception and through recollection. Neither sort of knowledge is transmittable solely through teaching nor acquired solely through perception.

I have argued for a particular doctrine of knowledge in Plato's writings. ${ }^{7}$ An understanding of this doctrine has aided in interpreting the

7If the doctrine of knowledge and the philosophy of education that I have
argued for are to hold up, my account of each must be consistent with the
writings of the later dialogues. Additional support for my interpretation of
the Platonic philosophy of education is to be found in the Laws. Like the
Republic, the Laws has much to say about education. Education is
described as including instruction and admonition (7.788). True education
requires practice of necessary preliminary instruction (1.643b-e) and is
self-correcting (1.644). Such preliminary instruction is compulsory for all
child ren (7.804e) and will be composed of training in music and
gymnastics (2.672). Clearly, Plato's philosophy of education in the Laws is
consistent with his philosophy of education in the Republic.

Support of my interpretation for the Platonic doctrine of knowledge can be found in the discussion of knowledge in Philebus. Early 
obscure jury refutation. If the project of the Theaetetus is taken to be the search for what is common to all sorts of knowledge, the apparent commonality is that whenever we know something, we know its essential nature. With further research, a connection between this commonality and the third definition of true belief plus logos may be established and the Combined Doctrine enriched.

in this dialogue, Socrates maintains that "knowledge taken in its entirety will seem to be a plurality in which this knowledge is unlike that ..." (13e7-8). Knowledge is divided into technical knowledge of the handicrafts and knowledge concerned with education (55d). Technical knowledge is further divided into superior knowledge involving precision and the inferior, limited knowledge of the numbers and kinds of letters and musical notes that is a basic requirement for reading and music (17b). Most interesting in the discussion of knowledge in the Philebus are two passages that mesh with the plurality of knowledge of external objects and knowledge of the forms. The first is a rather lengthy passage that describes the mental dialectical process. Once an object is perceived, one uses this process in order to make a judgment about the object $(38 \mathrm{c}-\mathrm{e})$. Here, I interpret Plato to be describing the mental activity required for the apprehension of the existence of a perceptual object. The second interesting passage describes the most exact sort of knowledge: "the cognition of that which is, that which exists in reality, ever unchanged." (57b) This is a clear reference to the knowledge of the forms. The Philebus, then, evidently supports the doctrine of knowledge $I$ have been advocating. 